\title{
Magnetic resonance imaging of primary spinal anaplastic oligoastrocytoma (World Health Organization Grade I I I) in an adult: A case report
}

\author{
Hongyue Tao ${ }^{1}$, Rong Lu ${ }^{1}$, Bo Yin ${ }^{1}$, Hong Chen ${ }^{2}$, Bing Sun ${ }^{3}$, Shuang Chen ${ }^{1}$ \\ 1. Department of Radiology, Huashan Hospital, Fudan University, Shanghai, China. 2. Department of Pathology, Huashan \\ Hospital, Fudan University, Shanghai, China. 3. Department of Neurosurgery, Huashan Hospital, Fudan University, \\ Shanghai, China \\ Correspondence: Shuang Chen. Address: Department of Radiology, Huashan Hospital, Fudan University, 12 \\ Wulumuqizhong Road, Shanghai, China. Email: chenshuang6898@126.com
}

Received: November 24, 2014

Accepted: January 26, 2015 Online Published: March 10, 2015

DOI : $10.5430 /$ ijdi.v2n2p15

URL: http://dx.doi.org/10.5430/ijdi.v2n2p15

\begin{abstract}
Primary anaplastic oligoastrocytoma (AOA) of spinal cord is very rare, and little is known about its MRI features. We reported a 40-year-old man complaining of numbness in his upper and distal limbs with slight hypesthesia. MRI revealed an intramedullary occupation extending from $\mathrm{C} 4$ to $\mathrm{C} 7$. Histological examination revealed an OA with anaplastic findings. Genetic analysis revealed loss of heterozygosity $(\mathrm{LOH})$ of $1 \mathrm{p}$ and $19 \mathrm{q}$. This is the first case of spinal AOA that has occurred in an adult. We present this case here to help radiologists realize the MRI characteristics of primary spinal AOA and even recognize this entity when making a diagnosis.
\end{abstract}

\section{Keywords}

Anaplastic oligoastrocytoma, Intramedullary tumor, MRI

\section{I ntroduction}

The most common spinal intramedullary tumors are astrocytomas and ependymomas. Primary oligodendroglioma of spinal cord is rare and primary spinal oligoastrocytoma $(\mathrm{OA})$ is even more rarer ${ }^{[1-3]}$. OA is a mixed glioma composed of distinct neoplastic astrocytic and oligodendroglial components ${ }^{[4]}$. The tumor is commonly located in the cerebral hemisphere which is about $53 \%$ in the frontal lobe and $38 \%$ in the temporal lobe involvement ${ }^{[4]}$. However, it is rarely presented in the spinal cord. Anaplastic oligoastrocytoma (AOA) is one type of OA with malignant features, such as an increase in cell density and heteromorphism. It is ranked as World Health Organization (WHO) grade III.

In this report, we described a very rare case of primary spinal AOA in a 40-year-old man who complained of numbness of his upper and distal limbs with slight hypesthesia. Magnetic resonance imaging (MRI) revealed an intramedullary occupation extended from $\mathrm{C} 4$ to $\mathrm{C} 7$, which was focally heterogeneously enhanced. The patient underwent $\mathrm{C} 4$ to $\mathrm{C} 7$ laminoplastic laminotomy and gross total removal of the tumor. Histological examination revealed an OA with anaplastic findings. Genetic analysis revealed the loss of heterozygosity (LOH) of $1 \mathrm{p}$ and 19q, which is characteristic of 
oligodendroglial tumors ${ }^{[5-8]}$. In this case, no other lesions were found before or after surgical treatment, indicating a primary spinal tumor.

Although cases of OA were reported before ${ }^{[3,9,10]}$, to our best knowledge, this is the first case of spinal AOA (WHO Grade III) which has occurred in an adult. Additionally, detailed MRI performances of OA or AOA were not provided in those reports. Since primary AOA of spinal cord is very rare and little is known about its MRI features, it was difficult to confirm the diagnosis of AOA by spinal MR imaging. Herein, we present this case to help radiologists realize the MRI characterristics of primary spinal AOA, and even recognize this entity when making diagnosis. This case report has been approved by our Institutional Review Board with patient informed consent.

\section{Case report}

A 40-year-old man presented with numbness of his left hand for 40 days, which gradually progressed to his left upper arm accompanied with superficial hypesthesia. Twenty days after onset of the symptom, he had numbness of bilateral distal limbs with slight superficial hypesthesia. Neurologic examination revealed hyperreflexia of the bilateral upper extremities, hyporeflexia of both patellar and achilles tendons, and reduced vibratory appreciation in both legs.
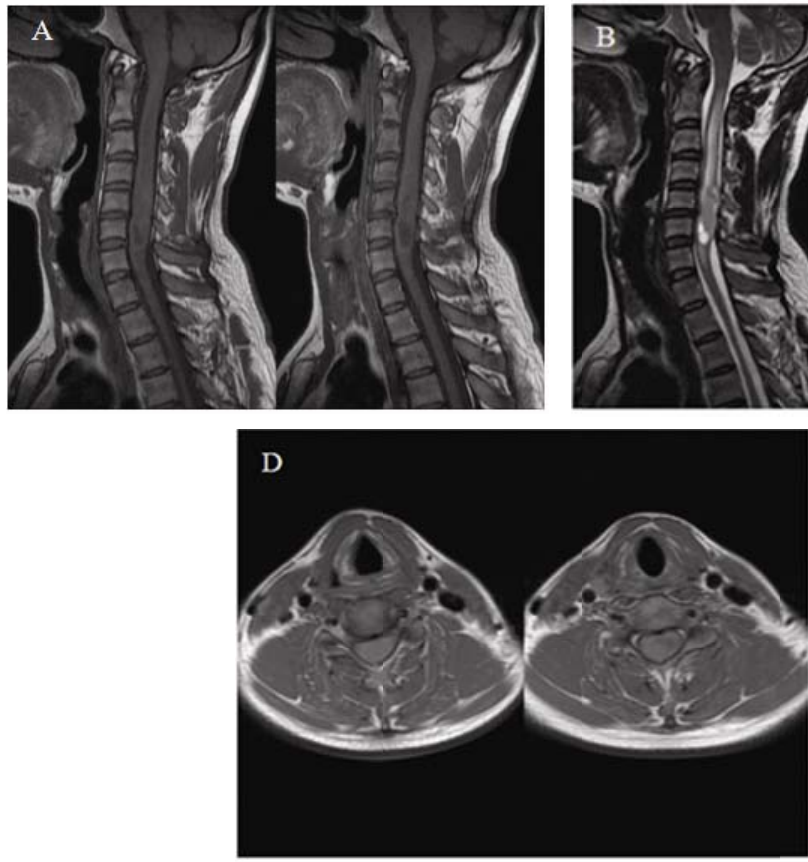
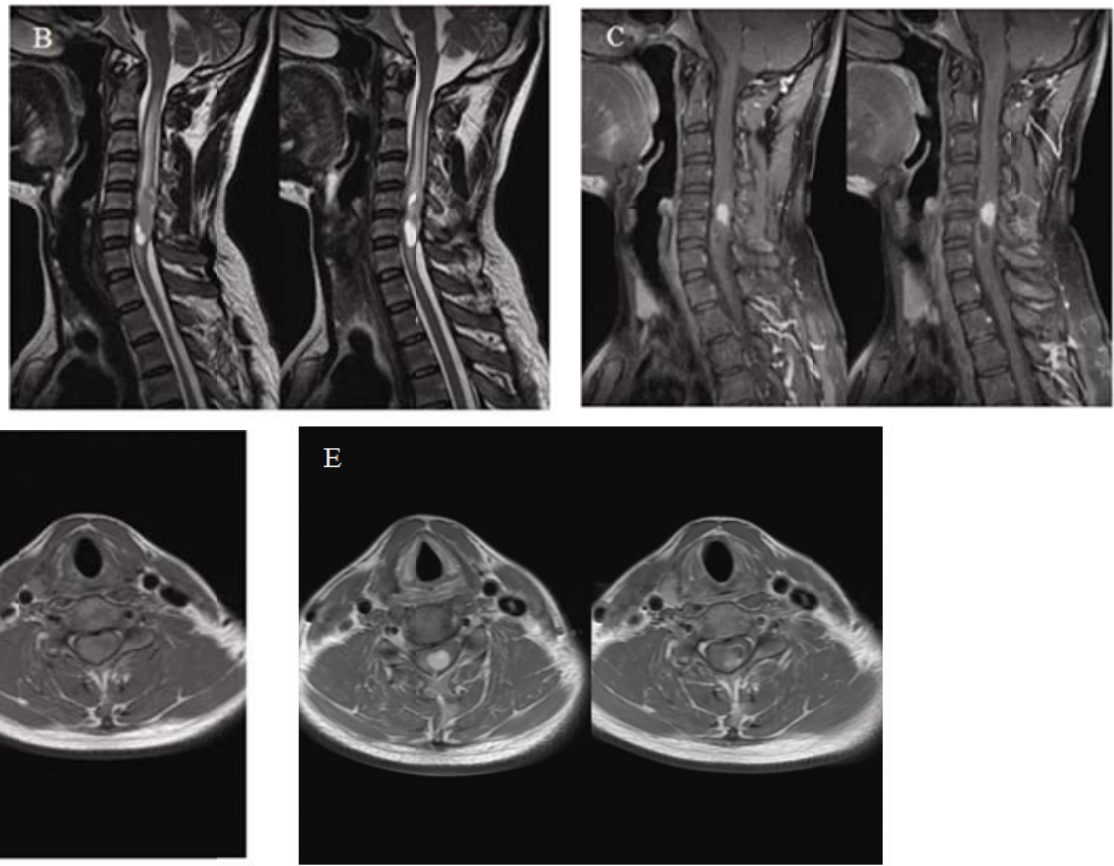

Figure 1. A. D. Sagittal and Axial T1WI showed enlargement of cervical spinal cord caused by an intramedullary cystic-solid lesion extending from $\mathrm{C} 4$ to $\mathrm{C} 6$. The solid portion was isointensity and the cystic portion was hypointensity; B. Sagittal T2WI showed the lesion was slight hyperintensity within solid component and obvious hyperintensity within cystic component. The lesion associated with spine syringomyelia (form $\mathrm{C} 2$ to $\mathrm{C} 7$ ) had poorly defined margins. Edematous signal surrounding the lesion could be observed; $\mathrm{C}$. E. After contrast, the lesion was heterogeneously enhanced as a mixture of nodular shape and circular shape. The solid portion was obviously homogeneously enhanced and slightly speckled enhancement could be observed around it. The cystic wall was ring-like enhanced

\subsection{MRI performances}

The patient performed a MRI study of his cervical spine. Sagittal and Axial T1-weighted images (T1WI) showed enlargement of the cervical spinal cord caused by an intramedullary cystic-solid lesion extending from C4 to C6. The solid portion was isointensity and the cystic portion was hypointensity (see Figure 1A and 1D). Sagittal T2-weighted images (T2WI) showed the lesion was slight hyperintensity within solid component and obvious hyperintensity within cystic 
component. The lesion associated with spine syringomyelia (from $\mathrm{C} 2$ to $\mathrm{C} 7$ ) had poorly defined margins. Edematous signal surrounding the lesion could be observed (see Figure 1B). After injection of gadolinium, the lesion was heterogeneously enhanced and appeared to be a mixture of nodular shape and circular shape, which also had poorly delineated margins. The solid portion was obviously homogeneously enhanced, and slightly speckled enhancement could be observed around it. The cystic wall was circular enhancement (see Figure 1C and 1E). Then a MRI study of head and thoraco-lumbar spinal cord was performed on this patient, which revealed no obvious abnormalities. At that time, the radiological diagnosis was preferred to primary cervical ependymoma with spine syringomyelia.

\subsection{Surgery procedure}

The patient received C4 to C7 laminoplastic laminotomy in Department of Neurosurgery of our hospital. After exposure of the tumor, a grayish-pink, soft, and infiltrating intramedullary tumor with the size of $3 \mathrm{~cm} \times 2 \mathrm{~cm} \times 1 \mathrm{~cm}$ could be observed. There was abundant blood supply in the solid portion of the tumor. The cystic portion was light yellow and had gelatinous fluid inside. Then the patient underwent gross total removal of the tumor.

\subsection{Pathology}

Sections from the surgical specimen were evaluated with routine hematoxylin-eosin (H-E) staining, which revealed oligodendrocytic cells with a honeycomb appearance and astrocytic cells with significant nuclear atypia (see Figure $2 \mathrm{~A}$ and 2B). In some parts of the tumor tissue, two components intermingled and in other parts they existed separately. Relatively high mitoticactivity was present, and necrosis and microvascular proliferations were absent. The immunohistochemistry label showed positive GFAP and Olig2, which confirmed the tumor was composed of a conspicuous mixture of astrocytic cells and oligodendroglial cells (see Figure $2 \mathrm{C}$ and $\mathrm{D}$ ). To examine the proliferative activity of the tumor, MIB-1 and p53 immunostaining was performed. The labeling index of MIB-1 was 40\% (see Figure 2E), significantly higher than $7 \%$ of spinal OA reported by Shimizu T, et al. ${ }^{[3]}$. Positive p53 immunoreaction was observed in both astrocytic and oligodendroglial element. These findings were compatible with a diagnosis of OA with anaplastic findings, which corresponded to WHO Grade III. Therefore, the histological examination revealed an AOA (WHO Grade III). Frozen specimen was analyzed for the LOH of $1 \mathrm{p}$ and $19 \mathrm{q}$ by microsatellite analysis ${ }^{[11]}$. LOH of $1 \mathrm{p}$ and $19 \mathrm{q}$ was detected in the specimen, which is characteristic of oligodendroglial tumors ${ }^{[8]}$.
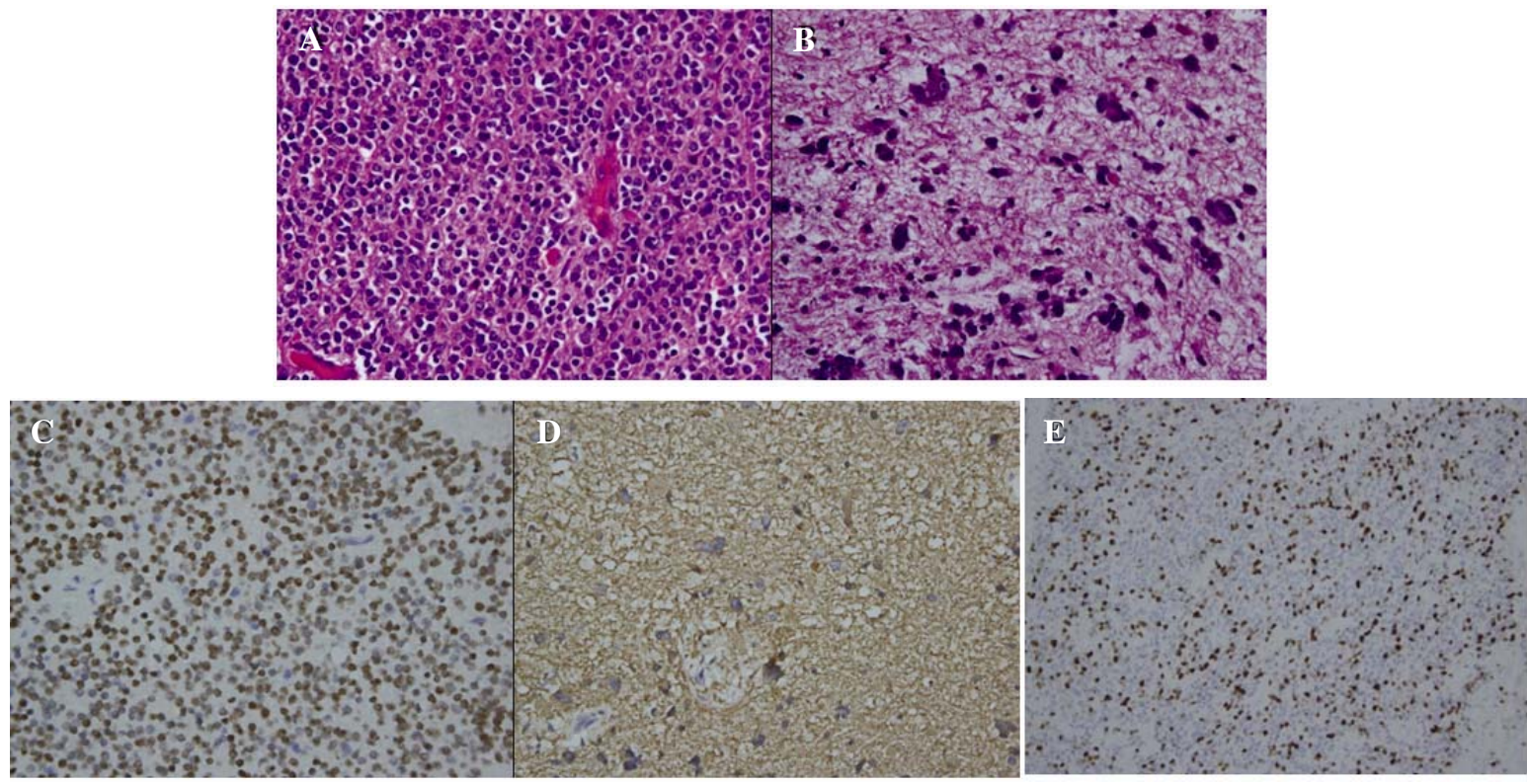

Figure 2. A. B. (magnification $\times 400$ ), H-E showed two different glial components: oligodendroglial component (A) and astrocytic component (B). Oligodendrocytic cells with honeycomb appearance and astrocytic cells with significant nuclear atypia. C. D. (magnification $\times 400$ ), The immunohistochemistry label showed positive Olig2 (C) and GFAP (D). E. (magnification $\times 200$ ), The labeling index of MIB-1 was $40 \%$ 


\subsection{Follow-up}

Postoperatively, the patient's neurologic status was uneventful. Since the effectiveness of postoperative adjunctive therapy for spinal AOA was uncertain, no radiation or chemotherapy was administered. He was discharged from hospital on the 6th postoperative day. The patient's first follow-up was 6 months post operation, and his MRI study showed postoperative changes with no evidence of tumor residual or recurrence.

\section{Discussion}

Since the reporting of the first primary spinal OA by Constantini S, et al. (1996, a child under 3-year-old) ${ }^{[10]}$, the first spinal AOA by Michałowska M, et al. (2000, a 10-year-old girl) ${ }^{[9]}$, and the third spinal OA by Shimizu T, et al. (2004, a 49-year-old woman ${ }^{[3]}$, herein, we reported an additional case of spinal AOA in an adult and increased the total number of spinal OA to 4, AOA to 2. This case report illustrated the MRI features of AOA in spinal cord which could help radiologists use MRI to characterize primary spinal AOA in diagnosis.

\subsection{MRI features and differential diagnosis}

On MR images, a spinal AOA was an intramedullary cystic-solid lesion with focal enlargement of cervical spinal cord. The lesion associated with spine syringomyelia had poorly delineated margins. It was heterogeneously enhanced as a mixture of nodular shape and circular shape after contrast. The MRI study of a primary spinal OA reported by Shimizu T, et al. showed enlargement of spinal cord caused by an isointense intramedullary lesion on T1WI. T2WI showed the lesion having a slightly high intensity with cystic components which are associated with whole spine syringomyelia ${ }^{[3]}$. After contrast, the lesion was heterogeneously enhanced. Thus, we summarized the similar features of these two primary spinal OA's by saying that maybe OA's are characterized by poorly delineated cystic-solid lesion associated with enlargement of spinal cord and spine syringomyelia, and heterogeneous enhancement after contrast. Additionally, compared to OA, AOA has a larger cystic area and more significant enhancement due to its anaplastic feature.

The MRI differential diagnosis of primary intramedullary OA/AOA includes ependymoma, astrocytoma and hemangioblastoma ${ }^{[12-15]}$, which account for about $4 \%$ to $10 \%$ of all central nervous system tumors ${ }^{[16]}$. The most common types of spinal cord are ependymoma in adults and astrocytoma in children, with both constituting up to $70 \%$ of all intramedullary neoplasms ${ }^{[16]}$. OA/AOA has a rather similar manifestation with ependymoma and astrocytoma. Ependymoma commonly show signs of necrosis (heterogeneity, cyst formation) and hemorrhaging (hyperintensity on T1WI, susceptibility artifact, hemosiderin "cap sign") ${ }^{[17]}$. Astrocytoma normally presents with fusiform enlargement of spinal cord, infiltrative margins, long segment of involvement, and slightly heterogeneous enhancement. It is commonly located in the cervical and upper thoracic cord ${ }^{[17,18]}$. Hemangioblastoma is the third most common type of primary spinal tumors. It is a hypervascular tumor with obvious enhancement and is usually located dorsally within spinal cord. This kind of tumor is often accompanied with signs of prior hemorrhage and prominent serpiginous subarachnoid flow voids due to enlarged draining veins ${ }^{[19]}$.

Besides, OA/AOA should be differentiated from intramedullary non-neoplastic lesions including demyelinating, vascular, and infectious diseases. Diffusive, peripheral, or speckled contrast enhancement or lack of contrast enhancement may suggest non-neoplastic lesions.

Above all, for the differential diagnosis, the patient's age, the topographic localization of the mass, the morphologic features and the enhancement pattern of the lesion as depicted by a MRI play important roles.

\subsection{Pathological features}

Diagnosis of OA requires the presence of two different neoplastic glial components ${ }^{[20]}$. In this case, the tumor tissue was composed of distinct GFAP-positive astrocytic cells and Olig2-positive oligodendroglial cells. Additionally, relatively high mitoticactivity was present, and necrosis and microvascular proliferations were absent. The labeling index of MIB-1 was $40 \%$, significantly higher than previous reports ${ }^{[3]}$. Positive p53 immunoreaction was observed in both astrocytic and 
oligodendroglial element. These anaplastic findings are the pathological features of AOA compared to OA. In addition, genetic analysis of our spinal AOA revealed the $\mathrm{LOH}$ of $1 \mathrm{p}$ and $19 \mathrm{q}$, which is another characteristics of spinal $\mathrm{OA} / \mathrm{AOA}^{[11,21]}$, and is compatible with spinal OA reported by Shimizu T, et al ${ }^{[3]}$.

\subsection{Therapy}

Several studies have revealed that the hemispheric OAs with LOH of $1 p$ and $19 q$ are usually associated with a longer survival time, as well as a better response to radiation and chemotherapy ${ }^{[22,23]}$. The overall survival time for hemispheric AOs is about 2-3 years for those without the LOH of $1 p$ and $19 q$, compared with 6-7 years in those with LOH of $1 p$ and $19 q^{[24]}$. As a result, genetic testing is now commonly obtained in patients with OA, and the results are often used in the decision process regarding radiation and chemotherapy ${ }^{[25]}$. Recently, the standard recommended therapy for hemispheric $\mathrm{OA}$ and $\mathrm{AOA}$ has been maximal resection, fractionated external beam radiation, and possibly $\mathrm{PCV}^{[26]}$. PCV therapy with procarbazine, lomustine, and vincristine has been reported to be effective for Grade III and IV OA ${ }^{[27]}$.

However, prognosis and effectiveness of radiation therapy and PCV for primary spinal AOA are uncertain because of its rarity. In order to avoid recurrence and improve prognosis, aggressive surgical resection of the tumor is the standard treatment ${ }^{[26,28]}$, yet the issue of adjunctive postoperative radiation therapy has remained controversial. For this patient, radiation and chemotherapy were not performed after his first operation due to the associated postradiation myelopathy, secondary tumors, and spinal deformity, as well as the lack of any evidence for the recommended dose ${ }^{[29]}$. He was advised to follow up twice a year. An early postoperative MRI study is beneficial in recognizing any residual or recurrence of the tumor. The MRI study of his first follow-up (6-months post operation) showed postoperative changes with no evidence of tumor residual or recurrence. If MRI results suggested the possibility of recurrence during follow-up, radiation and chemotherapy should be administered. Nevertheless, the future establishment of an international registry may be necessary for the better and more accurate understanding of this rare type of tumor.

\section{Conclusion}

Primary spinal AOA is quite a rare tumor, and this is the first report of spinal AOA (WHO Grade III) in an adult. The MRI of AOA is characterized by poorly delineated cystic-solid lesion associated with enlargement of spinal cord and spine syringomyelia, heterogeneously enhanced after contrast. It should be differentiated from ependymomas, astrocytomas and hemangioblastomas and intramedullary non-neoplastic lesions. The pathological feature of AOA is the presence of distinct neoplastic astrocytic and oligodendroglial components with anaplastic findings. In addition, genetic analysis revealed the $\mathrm{LOH}$ of $1 \mathrm{p}$ and 19q. Total resection of the tumor is the standard treatment. However, the prognosis and effectiveness of postoperative adjunctive therapy for spinal AOA was uncertain. Further investigations on the underlying mechanisms linking radiological and molecular characteristics are needed to provide better understanding of the nature of spinal AOA.

\section{Acknowledgement}

Hongyue Tao and Rong Lu contributed equally to this study and should be designated joint first-coauthors.

\section{References}

[1] Fountas KN, Karampelas I, Nikolakakos LG, et al. Primary spinal cord oligodendroglioma: case report and review of the literature. Childs Nerv Syst. 2005; 21(2): 171-5. PMid:15138790 http://dx.doi.org/10.1007/s00381-004-0973-8

[2] Miller DC. Surgical pathology of intramedullary spinal cord neoplasms. J Neurooncol. 2000; 47(3): 189-94. PMid:11016735 http://dx.doi.org/10.1023/A:1006496204396

[3] Shimizu T, Saito N, Aihara M, et al. Primary spinal oligoastrocytoma: a case report. Surg Neurol. 2004; 61(1): 77-81.

[4] Winger MJ, Macdonald DR, Cairncross JG. Supratentorial anaplastic gliomas in adults. The prognostic importance of extent of resection and prior low-grade glioma. J Neurosurg. 1989; 71(4): 487-93. PMid:2552044 http://dx.doi.org/10.3171/jns.1989.71.4.0487 
[5] Megyesi JF, Kachur E, Lee DH, et al. Imaging correlates of molecular signatures in oligodendrogliomas. Clin Cancer Res. 2004; 10(13): 4303-6. PMid:15240515 http://dx.doi.org/10.1158/1078-0432.CCR-04-0209

[6] Whitmore RG, Krejza J, Kapoor GS, et al. Prediction of oligodendroglial tumor subtype and grade using perfusion weighted magnetic resonance imaging. J Neurosurg. 2007; 107(3): 600-9. PMid:17886561 http://dx.doi.org/10.3171/JNS-07/09/0600

[7] Mueller W, Hartmann C, Hoffmann A, et al. Genetic signature of oligoastrocytomas correlates with tumor location and denotes distinct molecular subsets. Am J Pathol. 2002; 161(1): 313-9. http://dx.doi.org/10.1016/S0002-9440(10)64183-1

[8] Jeon YK, Park K, Park CK, et al. Chromosome 1p and 19q status and p53 and p16 expression patterns as prognostic indicators of oligodendroglial tumors: a clinicopathological study using fluorescence in situ hybridization. Neuropathology. 2007; 27(1): 10-20. PMid:17319279 http://dx.doi.org/10.1111/j.1440-1789.2006.00735.x

[9] Michalowska M, Jedrzejczak J, Krolicki L, et al. Anaplastic oligoastrocytoma of the spinal cord: diagnostic difficulties. Case report. Neurol Neurochir Pol. 2000; 34(5): 995-1004. PMid:11253487

[10] Constantini S, Houten J, Miller DC, et al. Intramedullary spinal cord tumors in children under the age of 3 years. J Neurosurg. 1996; 85(6): 1036-43. PMid:8929492 http://dx.doi.org/10.3171/jns.1996.85.6.1036

[11] Ueki K, Nishikawa R, Nakazato Y, et al. Correlation of histology and molecular genetic analysis of 1p, 19q, 10q, TP53, EGFR, CDK4, and CDKN2A in 91 astrocytic and oligodendroglial tumors. Clin Cancer Res. 2002; 8(1): 196-201. PMid:11801559

[12] Zenmyo M, Ishido Y, Terahara M, et al. Intramedullary subependymoma of the cervical spinal cord: a case report with immunohistochemical study. Int J Neurosci. 2010; 120(10): 676-9. PMid:20942580 http://dx.doi.org/10.3109/00207454.2010.509894

[13] Louis DN, Ohgaki H, Wiestler OD, et al. The 2007 WHO classification of tumours of the central nervous system. Acta Neuropathol. 2007; 114(2): 97-109. PMid:17618441 http://dx.doi.org/10.1007/s00401-007-0243-4

[14] Yadav RK, Agarwal S, Saini J, et al. Imaging appearance of subependymoma: a rare tumor of the cord. Indian J Cancer. 2008; 45(1): 33-5. PMid:18453739 http://dx.doi.org/10.4103/0019-509X.40645

[15] Krishnan SS, Panigrahi M, Pendyala S, et al. Cervical Subependymoma: A rare case report with possible histogenesis. J Neurosci Rural Pract. 2012; 3(3): 366-9. PMid:23189002 http://dx.doi.org/10.4103/0976-3147.102630

[16] Koeller KK, Rosenblum RS, Morrison AL. Neoplasms of the spinal cord and filum terminale: radiologic-pathologic correlation. Radiographics. 2000; 20(6): 1721-49. PMid:11112826 http://dx.doi.org/10.1148/radiographics.20.6.g00nv151721

[17] Kim DH, Kim JH, Choi SH, et al. Differentiation between intramedullary spinal ependymoma and astrocytoma: comparative MRI analysis. Clin Radiol. 2014; 69(1): 29-35. PMid:24034546 http://dx.doi.org/10.1016/j.crad.2013.07.017

[18] Rodriguez YBR, Di Ieva A, Colombo P, et al. Intramedullary astrocytoma with granular cell differentiation. Neurosurg Rev. 2007; 30(4): 339-43, 343.

[19] Imagama S, Ito Z, Wakao N, et al. Differentiation of localization of spinal hemangioblastomas based on imaging and pathological findings. Eur Spine J. 2011; 20(8): 1377-84. PMid:21528401 http://dx.doi.org/10.1007/s00586-011-1814-6

[20] Van Velthoven V, Calliauw L, Caemaert J. Intramedullary spread of a cerebral oligodendroglioma. Surg Neurol. 1988; 30(6): 476-81. http://dx.doi.org/10.1016/0090-3019(88)90035-3

[21] Smith JS, Perry A, Borell TJ, et al. Alterations of chromosome arms 1p and 19q as predictors of survival in oligodendrogliomas, astrocytomas, and mixed oligoastrocytomas. J Clin Oncol. 2000; 18(3): 636-45. PMid:10653879

[22] Cairncross JG. Cognition in survivors of high-grade glioma. J Clin Oncol. 1998; 16(9): 3210-1. PMid:9738601

[23] Cairncross JG, Ueki K, Zlatescu MC, et al. Specific genetic predictors of chemotherapeutic response and survival in patients with anaplastic oligodendrogliomas. J Natl Cancer Inst. 1998; 90(19): 1473-9. PMid:9776413 http://dx.doi.org/10.1093/jnci/90.19.1473

[24] Davis FG, McCarthy BJ, Freels S, et al. The conditional probability of survival of patients with primary malignant brain tumors: surveillance, epidemiology, and end results (SEER) data. Cancer. 1999; 85(2): 485-91. http://dx.doi.org/10.1002/(SICI)1097-0142(19990115)85:2<485::AID-CNCR29>3.0.CO;2-L

[25] Ino Y, Betensky RA, Zlatescu MC, et al. Molecular subtypes of anaplastic oligodendroglioma: implications for patient management at diagnosis. Clin Cancer Res. 2001; 7(4): 839-45. PMid:11309331

[26] Voloschin AD, Louis DN, Cosgrove GR, et al. Neoadjuvant temozolomide followed by complete resection of a 1p- and 19q-deleted anaplastic oligoastrocytoma: case study. Neuro Oncol. 2005; 7(1): 97-100. PMid:15701287 http://dx.doi.org/10.1215/S1152851704000560

[27] Kim L, Hochberg FH, Thornton AF, et al. Procarbazine, lomustine, and vincristine (PCV) chemotherapy for grade III and grade IV oligoastrocytomas. J Neurosurg. 1996; 85(4): 602-7. PMid:8814163 http://dx.doi.org/10.3171/jns.1996.85.4.0602

[28] Shaw EG, Scheithauer BW, O'Fallon JR, et al. Mixed oligoastrocytomas: a survival and prognostic factor analysis. Neurosurgery. 1994; 34(4): 577-82.

[29] Fountas KN, Karampelas I, Nikolakakos LG, et al. Primary spinal cord oligodendroglioma: case report and review of the literature. Childs Nerv Syst. 2005; 21(2): 171-5. PMid:15138790 http://dx.doi.org/10.1007/s00381-004-0973-8 